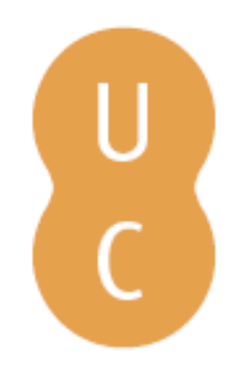

\title{
nombalina
}

\section{Análise SWOT do Ensino Superior Português: oportunidades, desafios e estratégias de qualidade}
Autor(es):
Comissão Setorial para a Educação e Formação; Grupo de Trabalho para a Gestão da Qualidade no Ensino Superior

Publicado por: Imprensa da Universidade de Coimbra

URL persistente:

URI:http://hdl.handle.net/10316.2/33292

DOI:

DOI:http://dx.doi.org/10.14195/978-989-26-0830-3

Accessed : $\quad$ 29-May-2015 11:37:55

A navegação consulta e descarregamento dos títulos inseridos nas Bibliotecas Digitais UC Digitalis, UC Pombalina e UC Impactum, pressupõem a aceitação plena e sem reservas dos Termos e Condições de Uso destas Bibliotecas Digitais, disponíveis em https://digitalis.uc.pt/pt-pt/termos.

Conforme exposto nos referidos Termos e Condições de Uso, o descarregamento de títulos de acesso restrito requer uma licença válida de autorização devendo o utilizador aceder ao(s) documento(s) a partir de um endereço de IP da instituição detentora da supramencionada licença.

Ao utilizador é apenas permitido o descarregamento para uso pessoal, pelo que o emprego do(s) título(s) descarregado(s) para outro fim, designadamente comercial, carece de autorização do respetivo autor ou editor da obra.

Na medida em que todas as obras da UC Digitalis se encontram protegidas pelo Código do Direito de Autor e Direitos Conexos e demais legislação aplicável, toda a cópia, parcial ou total, deste documento, nos casos em que é legalmente admitida, deverá conter ou fazer-se acompanhar por este aviso. 
CS/11 - COMISSÃO SETORIAL PARA A EDUCAC̣ÃO E FORMAÇÃO

GT2 - GRUPO DE TRABALHO PARA A GESTÃO DA QUALIDADE NO ENSINO

SUPERIOR

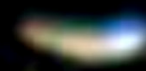
IMPRENSA DA UNIVERSIDADE DE COIMBRA COIMBRA UNIVERSITY PRESS

\section{(1)}

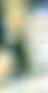

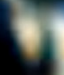

\section{SIDADE DE COIMBRA}




\section{EDIÇÃO}

Imprensa da Universidade de Coimbra

Email: imprensauc@ci.uc.pt

URL: http//www.uc.pt/imprensa_uc

Vendas online: http://livrariadaimprensa.uc.pt

\section{COORDENAÇÃO EDITORIAL}

Imprensa da Universidade de Coimbra

\section{CONCEPÇ̃̃o GRÁFICA}

António Barros

PRÉ-IMPRESS Ão

Mickael Silva

ISBN DIGITAL

978-989-26-0830-3

DOI

http://dx.doi.org/10.14195/978-989-26-0830-3 
CS/11 - COMISSÃO SETORIAL PARA A EDUCACุÃO E FORMAC̣ÃO

GT2 - GRUPO DE TRABALHO PARA A GESTÃO DA

QUALIDADE NO ENSINO

SUPERIOR
IMPRENSA DA UNIVERSIDADE DE COIMBRA COIMBRA UNIVERSITY PRESS

\section{ANÁLISE SWOT DO ENSINO SUPERIOR PORTUGUÊS:}

OPORTUNIDADES, DESAFIOS E ESTRATÉGIAS DE QUALIDADE 
(Página deixada propositadamente em branco) 


\section{S U M Á R I O}

PREFÁCIO

GRUPO DE TRABALHO PARA A GESTÃO DA QUALIDADE

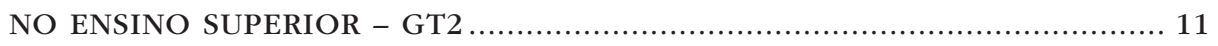

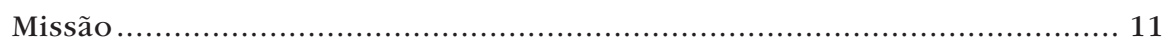

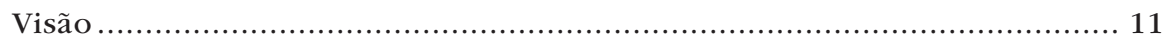

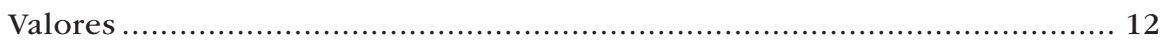

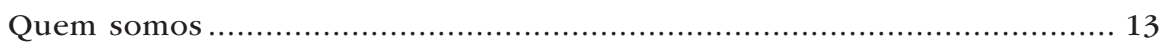

Trabalho desenvolvido em 2013 ............................................. 15

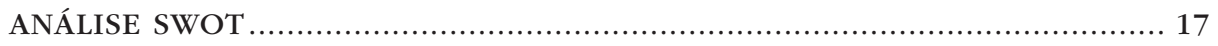

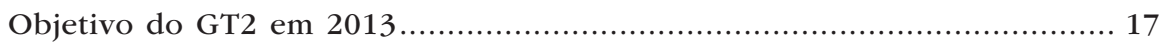

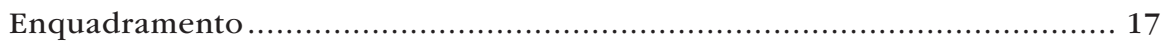

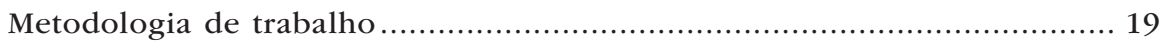

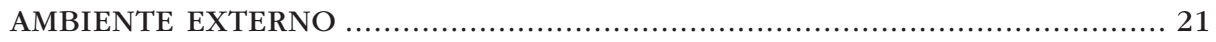

O que são ameaças e oportunidades? ......................................... 21

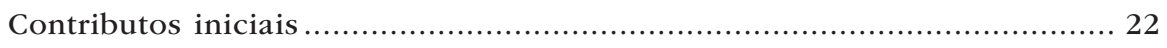

Enquadramento: o contexto do Ensino Superior português.................... 23

Ameaças e oportunidades identificadas ........................................ 27

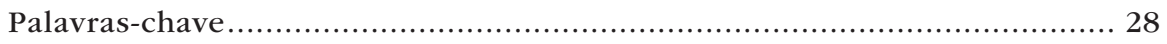

AMBIENTE INTERNO .......................................................... 29 
O que são pontos fortes e pontos fracos?.

Contributos iniciais .............................................................. 29

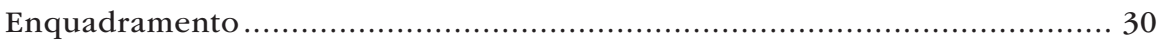

Pontos fortes e fracos identificados .......................................... 31

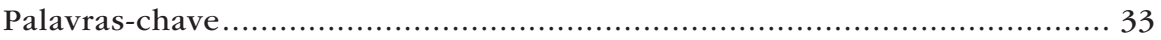

ENRIQUECIMENTO DA ANÁLISE SWOT ....................................... 35

Realização do inquérito aos estudantes ....................................... 35

Encontro do GT2 ............................................................... 35

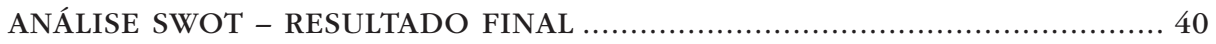

Ambiente interno e externo .................................................. 40

Matriz SWOT - sugestões de ação ............................................... 41

QUALIDADE E OPORTUNIDADES NO ENSINO SUPERIOR .................... 43 


\section{P R E F Á C I O}

A evolução do Ensino Superior português tem sido, ao longo das últimas décadas, pautada por amplas e profundas alterações. Em Portugal, desde a década de setenta do século XX, destaca-se o crescimento exponencial do sistema, traduzido no aumento do número de Instituições de Ensino Superior e no aumento, em número e diversidade, da capacidade instalada com a criação de novos programas e ciclos de estudo e novas áreas de formação. Destaca-se ainda a implementação do processo de Bolonha; a mudança do perfil socioeconómico dos estudantes e da sua situação perante o mercado de trabalho e, mais recentemente, o impacto da crise financeira no financiamento do sistema. Tendências gerais como a globalização e a democratização do acesso ao Ensino Superior, ou contextos específicos como o aumento da taxa de abandono escolar e a pressão para a empregabilidade dos diplomados, carecem de análise e reflexão com vista à adoção de medidas conjuntas ou institucionais para adequação de instrumentos e/ou princípios.

$\mathrm{Na}$ avaliação que faz do sistema de Ensino Superior português em 2006, a OCDE refere que os próximos passos deverão ser dados no sentido de fazer um melhor e mais eficiente uso dos recursos já existentes e não no sentido da expansão ou alargamento da rede, sugerindo que o caminho passará por uma maior consolidação da rede já existente. A rede das Instituições de Ensino Superior em Portugal parece estar sob fogo, numa agenda onde as palavras "reorganização", "racionalização" e "integração" têm prevalecido face a outras não menos relevantes como "internacionalização", "externalização" ou "Qualidade", etc. 
Neste cenário, urge refletir sobre o sistema de Ensino Superior existente no país, com um campo de visão alargado ao desenvolvimento de ações estratégicas que visem o fim último que, acredito, será partilhado por todas as instituições, independentemente da sua natureza: um Ensino Superior coeso, de maior qualidade, em constante melhoria e aperfeiçoamento, cujo mérito seja reconhecido além-fronteiras.

Alicerçada nestas preocupações, a obra aqui apresentada consubstancia o trabalho realizado pelo GT2 - Grupo de Trabalho para Gestão de Qualidade no Ensino Superior da Comissão Setorial para a Educação e Formação (CS/11), cuja mais-valia se traduz na construção de uma visão e reflexão partilhada pelas Instituições de Ensino Superior, públicas e privadas, representadas no Grupo. Não tendo a pretensão de ser uma obra fechada nem um manual teórico, aspira a lançar pistas e estratégias a seguir para melhorar o sistema do Ensino Superior, no percurso das instituições que nele reveem a sua utilidade.

Do trabalho desenvolvido pelo Grupo, uma ilação comum se pode retirar, como mote para atuação futura: um aumento da cooperação entre instituições possibilitará um reforço das redes colaborativas no sistema, aumentado a qualidade do Ensino Superior.

Margarida Mano Vice-Reitora da Universidade de Coimbra 


\section{CS/11 - COMISSÃO SETORIAL PARA A EDUCAÇÃO E FORMAÇ ÃO}

A Comissão Setorial para a Educação e Formação (CS/11), com o enquadramento legal atualmente previsto no Decreto-Lei $n .^{\circ} 71 / 2012$ de 21 de março, foi criada em novembro de 1996, no âmbito do Sistema Português da Qualidade (SPQ), tendo iniciado a sua atividade em fevereiro de 1997.

\section{A CS/11 tem como missão:}

- Analisar os vetores influentes da qualidade nas instituições de Educação e Formação;

- Promover e dinamizar sistemas e metodologias que permitam o planeamento, a gestão, a avaliação e a melhoria do desempenho das Instituições de Educação e Formação.

A CS/11 desenvolve a sua atividade no âmbito do Instituto Português da Qualidade e tem um projeto que visa identificar, analisar e disseminar os referenciais e as práticas de qualidade nas instituições de ensino e formação profissional.

$100^{\mathrm{a}}$ Reunião da CS/11 


\section{Composição:}

A CS/11 é constituída por cerca de 30 membros representantes de diversas entidades, nomeadamente associações, escolas e outros organismos e instituições do setor da Educação e Formação.

Mensalmente são realizadas reuniões com todos os elementos da comissão e, paralelamente, constituídos grupos de trabalho responsáveis pela dinamização de temáticas específicas sobre a qualidade na Educação e Formação.

A CS/11 é constituída pelos seguintes grupos de trabalho:

- GT1 - Educação e Formação

- GT2 - Ensino Superior

- GT3 - Website e Comunidade Virtual 
GRUPO DE TRABALHO PARA A GESTÃO DA

QUALIDADE NO ENSINO SUPERIOR - GT2

O Grupo de Trabalho para a Gestão da Qualidade no Ensino

Superior (GT2) é um dos 3 grupos constituintes da Comissão Setorial para a Educação e Formação (CS/11).

O grupo tem como principal objetivo informar, despertar o entusiasmo, e promover a adesão a boas práticas na área da Gestão da Qualidade no Ensino Superior, através da difusão de informação junto das comunidades académica e científica.

\section{Missão}

- Analisar os vetores influentes da qualidade nas instituições de Ensino Superior portuguesas;

- Promover e dinamizar sistemas e metodologias que permitam o planeamento, a gestão, a avaliação e a melhoria do desempenho das Instituições de Ensino Superior.

Visão

Ser um grupo de referência na área da qualidade no Ensino Superior português. 


\section{Valores}

- Respeito e Confiança: impulsores de uma relação autêntica entre os elementos do grupo, permitem o estabelecimento e manutenção de um relacionamento duradouro, que estimula o trabalho em equipa e a troca de experiências;

- Solidariedade e Partilha: dinamizando parcerias e promovendo a reflexão crítica, a partilha de ideias e experiências, estes valores sustentam uma atitude participativa e de interajuda entre os elementos do GT2;

- Qualidade e Inovação: com estes valores em mente, procuramos em cada momento novas respostas, diferentes estratégias e novos modos de trabalhar que possam contribuir para a melhoria contínua do Ensino Superior português. 


\section{QUEM SOMOS}

\begin{tabular}{|c|c|c|}
\hline Instituição & Representante & Contacto \\
\hline $\begin{array}{l}\text { Instituto Superior Técnico, } \\
\text { Universidade Técnica de } \\
\text { Lisboa } \\
\text { Coordenação do GT2 }\end{array}$ & $\begin{array}{l}\text { Alexandra Sevinate Pontes } \\
\text { Coordenadora } \\
\text { Marta Pile } \\
\text { Coordenadora Adjunta }\end{array}$ & \begin{tabular}{|l|} 
alexandra.pontes@tecnico. \\
alisboa.pt \\
marta.pile@tecnico. \\
alisboa.pt
\end{tabular} \\
\hline $\begin{array}{l}\text { Agência de Avaliação e } \\
\text { Acreditação do Ensino } \\
\text { Superior (A3ES) }\end{array}$ & Madalena Fonseca & madalena.fonseca@a3es.pt \\
\hline $\begin{array}{l}\text { Escola Superior de Educação } \\
\text { Paula Frassinetti }\end{array}$ & $\begin{array}{l}\text { José Luís Gonçalves || } \\
\text { (Paula de Medeiros) }\end{array}$ & \begin{tabular}{|l} 
oseluis@esepf.pt \\
pcristinacpmedeiros@ \\
gmail.com
\end{tabular} \\
\hline Instituto Piaget & Marlene Vale da Silva & $\begin{array}{l}\mid \text { pres.conselhodirectivo@ } \\
\text { isboa.ipiaget.org }\end{array}$ \\
\hline $\begin{array}{l}\text { Instituto Politécnico de Viana } \\
\text { do Castelo }\end{array}$ & Ana Sofia Rodrigues & qualidade@ipvc.p \\
\hline Instituto Politécnico do Porto & Cristina Pinto da Silva & csilva@sc.ipp.pt \\
\hline $\begin{array}{l}\text { Associação Portuguesa do } \\
\text { Ensino Superior Privado } \\
\text { (APESP), Instituto Superior D. } \\
\text { Afonso III }\end{array}$ & Ventura de Mello-Sampayo & vsampayo@gmail.com \\
\hline $\begin{array}{l}\text { Instituto Superior de Paços de } \\
\text { Brandão }\end{array}$ & Pedro Valente & gaq@ispab.p \\
\hline IPAM, the Marketing School & $\mathrm{He}$ & hpires@ipam.pt \\
\hline $\begin{array}{l}\text { Universidade Europeia } \\
\text { | Laureate International } \\
\text { Universities }\end{array}$ & José Reis & ose.reis@europeia.pt \\
\hline Universidade Aberta & Carla Farinha & carla.farinha@uab.pt \\
\hline $\begin{array}{l}\text { Universidade Autónoma de } \\
\text { Lisboa }\end{array}$ & João Vela Bastos & $\begin{array}{l}\text { bastos@universidade- } \\
\text { autonoma.pt }\end{array}$ \\
\hline $\begin{array}{l}\text { Universidade Católica } \\
\text { Portuguesa, Faculdade de } \\
\text { Ciências Humanas }\end{array}$ & Cristina Salgado & csalgado@fch.ucp.pt \\
\hline Universidade da Beira Interior & Luís Lourenço & lourenco@ubi.pt \\
\hline Universidade de Aveiro & Gillian Moreira & gillian@ua.pl \\
\hline Universidade de Coimbra & Margarida Mano & mimano@fe.uc.p \\
\hline Universidade de Lisboa & Valentina Oliveira & qualidade@reitoria.ul.pt \\
\hline Universidade do Minho & Isabel Santos & \begin{tabular}{|l|} 
sec-gdias@reitoria. \\
uminho.pt \\
\end{tabular} \\
\hline Universidade Lusófona & Célia Pires & celia.pires@ulusofona.pt \\
\hline $\begin{array}{l}\text { Universidade Nova de Lisboa, } \\
\text { Faculdade de Ciências e } \\
\text { Tecnologia }\end{array}$ & $\begin{array}{l}\text { Ana Falcão || Catarina } \\
\text { Silva Pinto }\end{array}$ & $\begin{array}{l}\text { ana.falcao@unl.pt || } \\
\text { cpinto@unl.pt }\end{array}$ \\
\hline Universidade Portucalense & Maria das Dores Formosinho & \begin{tabular}{|l|} 
mformosinhosanches 9 \\
gmail.com \\
\end{tabular} \\
\hline $\begin{array}{l}\text { Universidade Técnica de } \\
\text { Lisboa (Reitoria) }\end{array}$ & Luísa Neves & heves@reitoria.utl.pt \\
\hline
\end{tabular}

O GT2 agradece a colaboração especial neste projeto dos estagiários da Universidade de Coimbra Helena Rolas e Ricardo Mendes.

Nota: atualizado em junho de 2013. 


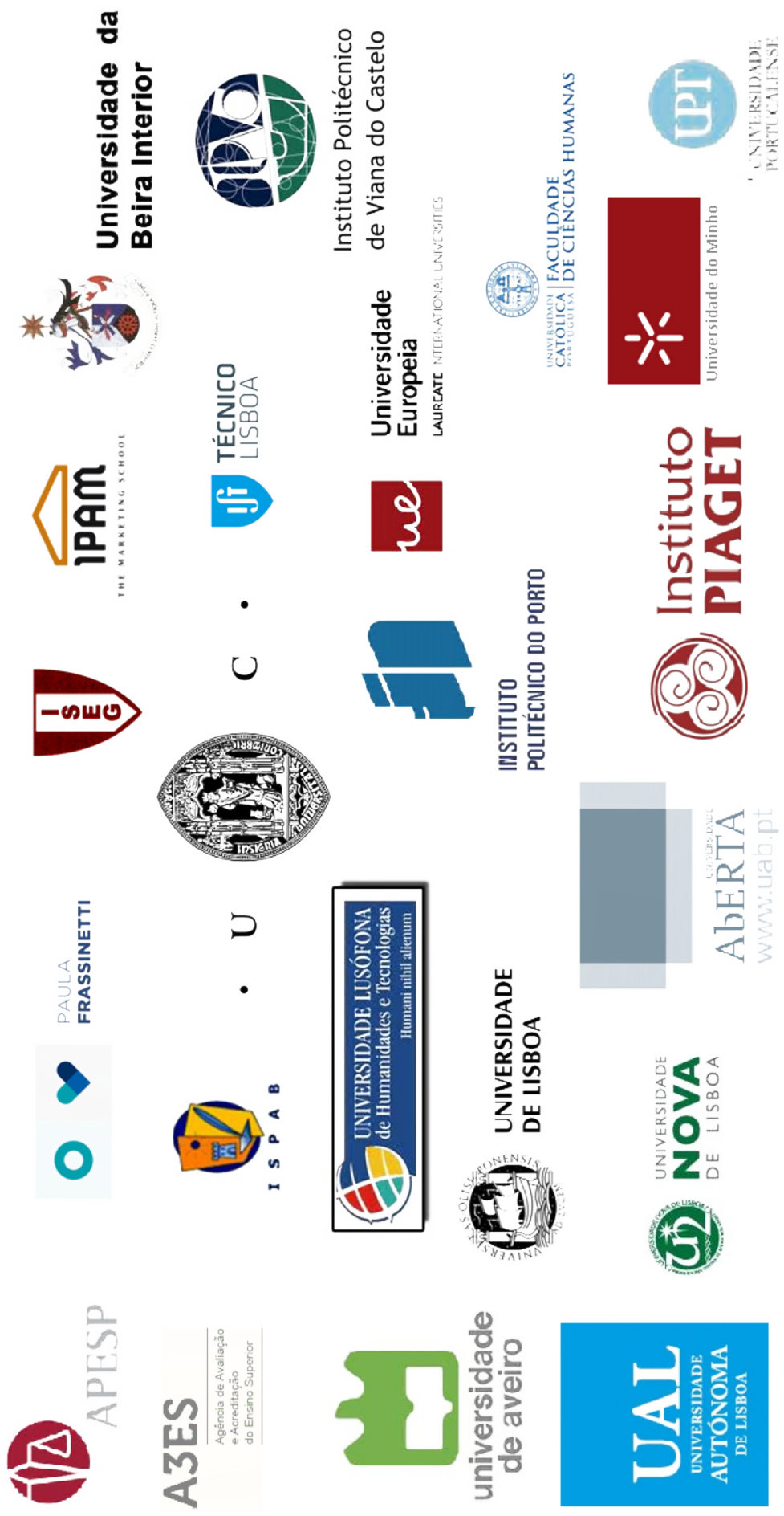


Trabalho desenvolvido em 2013

Dinamização de debates internos

Fases de elaboração do Plano e Manual da Qualidade numa IES: IPAM ISEG

Henrique Pires e Vítor Palmela Ramos, fevereiro de 2013

\section{Auditorias A3ES}

Marta Pile, abril de 2013

Análise SWOT do Ensino Superior Português - Ambiente externo Pedro Lourtie, abril de 2013

Análise SWOT do Ensino Superior Português - Ambiente interno António Câmara, maio de 2013

A Qualidade no Ensino Superior: que sugestões? Benchmarking da $\operatorname{CS11}$

Helena Rolas e Ricardo Mendes, sessão de julho de 2013

Apresentação do e-book "Aferição da Qualidade no Ensino Superior. Exemplos de Boas Práticas'

Alexandra Sevinate Pontes e Marta Pile, sessão de setembro de 2013

Sessão temática

Encontro "Análise SWOT do Ensino Superior Português: Oportunidades, Desafios e Estratégias de Qualidade"

IPAM, Porto, 13 de novembro de 2013

Conheça os pormenores â frente. 
(Página deixada propositadamente em branco) 


\section{A NÁLISE SWOT}

\section{Objetivo do GT2 em 2013}

No ano de 2013 o GT2 assumiu como objetivo desenvolver uma Análise SWOT do Ensino Superior português.

Com esta análise, o GT2 pretendeu construir uma ferramenta de diagnóstico que ajudasse a uma avaliação do sistema de Ensino Superior em Portugal, bem como à definição de algumas ações e estratégias a seguir neste contexto.

A Análise SWOT construída pelo GT2:

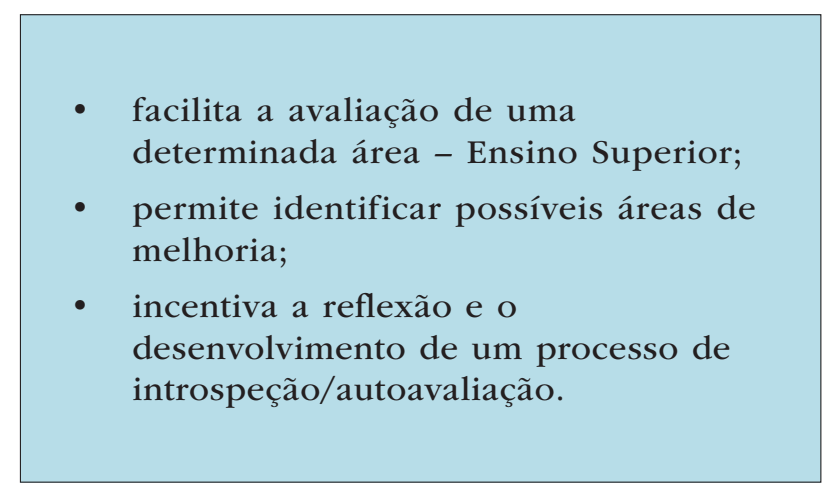

\section{Enquadramento}

A Análise SWOT é um meio de diagnóstico estratégico integrado no processo de melhoria contínua que facilita a avaliação de uma determinada área - Ensino Superior. 
SWO'T é uma sigla que contém as iniciais, em inglês, dos termos: pontos fortes (Strengths), pontos fracos (Weaknesses), oportunidades (Opportunities) e ameaças (Threats).

Reflete uma perspetiva global da situação em que se encontra determinada organização, permitindo a identificação de estratégias e ações de melhoria, auxiliando assim à definição da estratégia da mesma.

A Análise SWOT pressupõe a divisão do ambiente em duas partes: ambiente interno e ambiente externo.

O ambiente interno é influenciável e gerido pela organização e é caraterizado por pontos fortes e por pontos fracos. Quanto ao ambiente externo, contém elementos que não podem ser previstos ou controlados pela organização, pelo que a sua análise permite a identificação de tendências que se traduzem em oportunidades e ameaças.

A Análise SWOT relaciona os pontos fortes e pontos fracos de uma instituição com as oportunidades e ameaças do seu meio envolvente.

Assim, e de forma resumida, pode dizer-se que a Análise SWOT visa essencialmente:

- atenuar os pontos fracos;

- reforçar os pontos fortes;

- aproveitar as oportunidades;

- olhar para as ameaças como potenciais oportunidades. 


\section{Metodologia de trabalho}

A análise SWOT foi elaborada em três passos:

Passo 1

Passo 2

Passo 3
Análise do ambiente externo do Ensino Superior: ameaças e oportunidades Análise das Instituições de Ensino Superior enquanto organizações complexas: pontos fortes e pontos fracos Cruzamento de sugestões / ações: análise SWOT

No total ocorreram 8 sessões de trabalho do GT2 para elaboração da Análise SWOT do Ensino Superior português. Além das sessões de trabalho do grupo, realizaram-se 3 sessões de reflexão (uma para cada passo da metodologia).

Para a prossecução desta metodologia, constituíram-se dois grupos de trabalho, de acordo com a natureza das Instituições de Ensino Superior (IES): pública e privada.

Os dois grupos realizaram uma reflexão crítica e discussão, e o resultado das mesmas foi depois confrontado com o objetivo último de criar uma matriz única para IES públicas e privadas, embora se tenham tido em conta algumas especificidades das duas realidades.

Passo 1

No que diz respeito ao primeiro passo, correspondente à análise do ambiente externo, realizaram-se 3 sessões com trabalhos de grupo do GT2. Realizou-se ainda 1 sessão de reflexão dinamizada pelo Professor Doutor Pedro Lourtie na reunião Plenária da CS/11, sob o mote: Que ameaças e

\section{oportunidades caraterizam o Ensino Superior em Portugal?.}

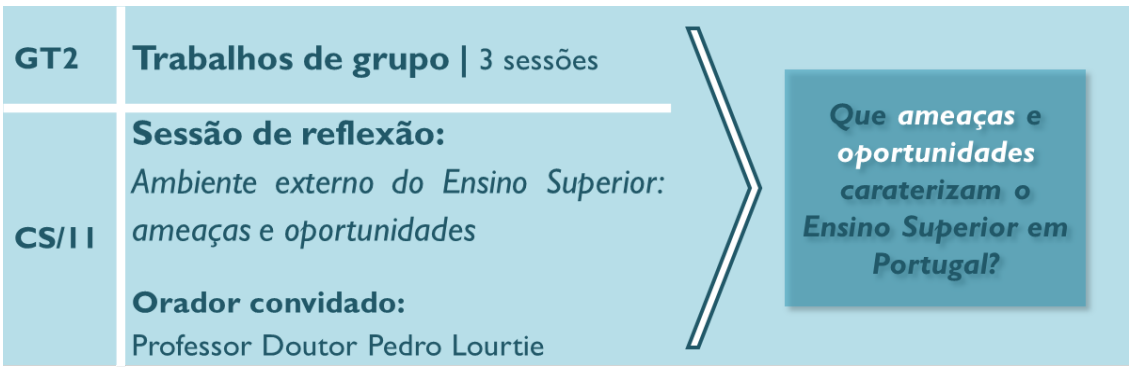


Relativamente ao segundo passo, análise do ambiente interno, foram realizadas 2 sessões com trabalhos de grupo do GT2 e uma sessão de reflexão denominada ఏnstituições do Ensino Superior enquanto organizações complexas: pontos fortes e pontos fracos, dinamizada pelo Professor Doutor António Câmara. A análise do ambiente interno permitiu, assim, identificar quais os pontos fortes e pontos fracos das IES portuguesas.

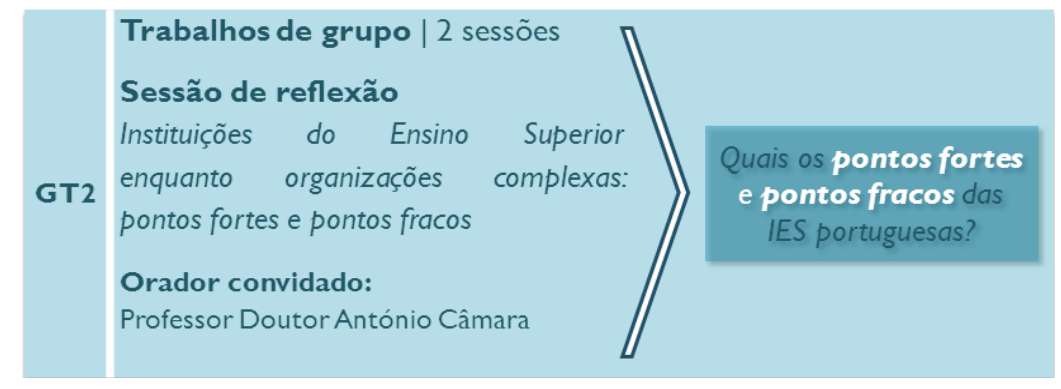

Passo 3

Por fim, no que diz respeito ao cruzamento de sugestões/ações, foram realizadas 3 sessões com trabalhos de grupo do GT2, e uma sessão de reflexão sobre Qualidade do Ensino Superior: que sugestões? - brainstorming, alargada à CS/11, para apresentação do trabalho aos restantes membros da Comissão e para recolha de sugestões/contributos.

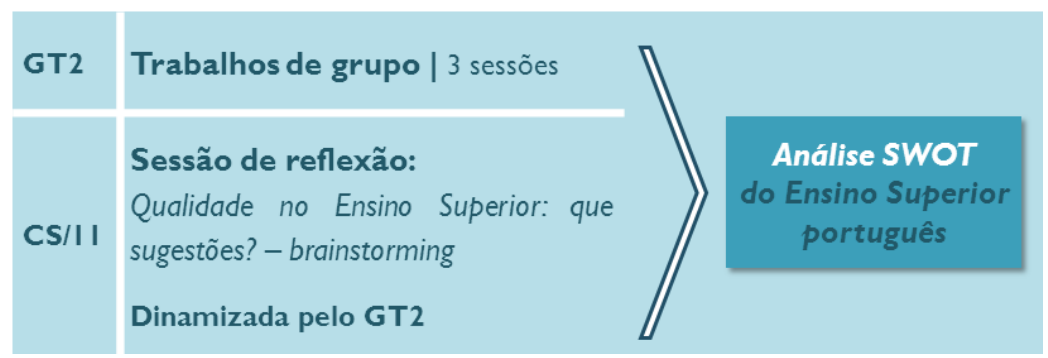




\section{AM B I ENT E EXTE R N O}

\section{O que são ameaças e oportunidades?}

As ameaças e oportunidades decorrem de tendências identificadas numa análise de ambiente externo.

As oportunidades são tendências, elementos ou acontecimentos, externos à organização mas dos quais esta pode tirar benefício/vantagem na medida em que podem ter impacto positivo sobre ela. Embora estejam fora do controlo da organização, as oportunidades devem ser consideradas no seu planeamento.

As ameaças são elementos potenciais, externos à própria organização, cujo impacto deve ser mitigado pela organização, na medida em que pode ser negativo para ela. Tal como as oportunidades, estão fora do controlo da organização. Convém, no entanto, referir que as ameaças podem sempre ser encaradas como oportunidades latentes. 


\section{Contributos iniciais}

\section{Reflexão individual dos membros do GT2}

Como base de discussão sobre o ambiente externo do ensino superior, foi pedido aos membros do GT2 que listassem, através de contributos individuais, as ameaças e oportunidades que caraterizam o Ensino Superior português.

Debate interno - Pedro Lourtie

Apresentação da sessão de reflexão Ambiente Externo do Ensino Superior: ameaças e oportunidades 


\section{Enquadramento: o contexto do Ensino Superior português}

Procede-se a uma breve caraterização do contexto do Ensino Superior português em termos demográficos e seu enquadramento no contexto da União Europeia a 27 (UE27), em termos da educação e estrutura das qualificações dos portugueses, bem como da dimensão dos desafios que ainda se colocam relativamente às necessidades de melhoria dos seus níveis de qualificação. Analisam-se ainda alguns dados sobre investigação e desenvolvimento e carateriza-se a oferta e procura do sistema de Ensino Superior em Portugal.

\section{1- Demografia}

De acordo com dados do Eurostat e do INE (2011), Portugal ocupa a $11^{a}$ posição na UE27, em termos de população residente.

Não obstante a população residente em Portugal entre 2001 e 2011, ter aumentado de 10.394669 para 10.542398 indivíduos, o país mantém a tendência de envelhecimento demográfico, traduzida numa redução dos efetivos populacionais jovens, como resultado da baixa da natalidade, a par com o acréscimo do número de pessoas idosas, devido ao aumento da esperança de vida.

\section{2- Educação e qualificações}

A educação em Portugal apresenta um cenário de contrastes. Se, por um lado, se atingem razoáveis níveis educativos na população jovem, por outro lado, refletindo um passado de grande atraso, persistem fracos índices de qualificação da população menos jovem, que se agravam de modo dramático à medida que se progride para escalões etários superiores. Aqui ficam alguns tópicos sobre a educação e qualificações dos portugueses:

$\checkmark$ As despesas do Estado português com educação em percentagem do PIB, na década de 2001 a 2012, situaram-se entre o pico de $5,2 \%$ em 2002 e os $4,0 \%$ em 2012.

$\checkmark$ Portugal, no rácio de alunos no total da população residente, em 2011, ocupa a $11^{a}$ posição na UE27, obtendo uma média de $22,1 \%$, ligeiramente superior à média europeia, que é de 21,5\%. 
$\checkmark \quad$ Na população entre os 25 e os 64 anos que tem pelo menos o ensino secundário, Portugal desce para a $27^{a}$ e última posição na UE27. A média de 35,0\% desta população com o ensino secundário fica visivelmente distante da média europeia, que se situa nos $73,4 \%$.

$\checkmark$ A taxa de abandono precoce da escola entre os 18 e 24 anos é de $23,2 \%$, a terceira mais elevada da UE27.

$\checkmark$ Considerando como qualificações muito baixas as que são iguais ou inferiores ao $1^{\circ}$ ciclo do Ensino Básico, em 2011 existem ainda cerca de 3,4 milhões de indivíduos, com 15 ou mais anos de idade, que não alcançaram um nível mínimo de literacia.

$\checkmark$ Considerando como baixas qualificações os indivíduos que completaram no máximo o $2^{\circ}$ ou $3^{\circ}$ ciclos do Ensino Básico (níveis 1 e 2 do quadro nacional de qualificações), em 2011 este grupo era constituído por quase 2,9 milhões de pessoas de 15 ou mais anos.

$\checkmark \quad$ Nas qualificações médias, correspondentes aos indivíduos detentores do nível secundário ou pós-secundário de educação (níveis 3, 4 e 5 do quadro nacional de qualificações), este grupo era constituído por 1,5 milhões de pessoas.

$\checkmark$ Os diplomados do Ensino Superior, no mesmo período, registaram um crescimento, representando, em 2011, 13,8\% dos indivíduos do escalão etário com 15 ou mais anos.

\section{3- Investigação e desenvolvimento}

O desenvolvimento do sistema científico e tecnológico nacional tem recebido um incentivo positivo num esforço continuado e persistente que resultou na sua expansão e aproximação, em muitos aspetos, da média europeia.

$\checkmark \quad$ Em Portugal as despesas em investigação e desenvolvimento (I\&D) receberam um forte incremento a partir de 2005, ano em que a percentagem representava 0,8 do $\mathrm{PIB}$, tendo crescido desde então a um ritmo de 15,9\% ao ano, situando-se em 1,5\% em 2011. Para 2012 os números apontavam para uma quebra, situando-se em 1,4\%. A média da UE27 é de 2,0\%. 
$\checkmark$ São as empresas que executam a maior parte da despesa com I\&D (47\%), cabendo ao Ensino Superior 38\% da despesa. Além disso, os serviços da administração central representam ainda $7 \%$, enquanto os restantes $8 \%$ são realizados por instituições privadas sem fins lucrativos.

$\checkmark$ O número de pessoas envolvidas em atividades de I\&D por 1.000 ativos tem vindo a crescer, colocando Portugal na $13^{\mathrm{a}}$ posição no âmbito da UE27, com uma média de 9,6 indivíduos por 1.000 ativos, em comparação com os 10,7 na UE27.

$\checkmark$ De acordo com os dados do último Inquérito ao Potencial Científico e Tecnológico Nacional (IPCTN12) o número total de investigadores, medido em "equivalente a tempo integral" (ETI), é de 50.694. Os investigadores concentram-se sobretudo no Ensino Superior, com 30.185 (ETI), seguindo-se o setor das empresas, com 12.117 (ETI).

$\checkmark$ Até final dos anos 80, o número de publicações por 100 mil habitantes foi sempre inferior a dez. Atualmente é de 131,6, ou seja, aumentou mais de dez vezes em 20 anos.

\section{4- Oferta e procura}

O Ensino Superior em Portugal é um sistema binário que integra universidades e institutos politécnicos, com instituições públicas (incluindo a Universidade Aberta e as instituições de ensino superior militares e policiais) e instituições privadas (abrangendo a Universidade Católica Portuguesa). Estas instituições apresentam estruturas de organização e dimensão diversificadas e de diferente natureza jurídica.

Alguns dados e números relevantes:

$\checkmark$ O sistema de Ensino Superior em Portugal é constituído por 133 instituições. Corresponde a um universo de 4.442 ciclos de estudos, com um total de 171.832 vagas (e cerca de 390 mil estudantes inscritos no ano letivo de 2010/11).

$\checkmark$ O Ensino Superior público, incluindo o ensino militar, representa quase $3 / 4$ dos ciclos de estudos ( $74 \%$ ), oferece $2 / 3$ do total de vagas (66\%), e concentra $77 \%$ dos estudantes inscritos no ano 2010/11. 
$\checkmark$ O Ensino Superior privado corresponde a cerca de 1/4 do total de ciclos de estudos do sistema, oferece $1 / 3$ das vagas e representa cerca de $1 / 5$ do total de inscritos, com $22 \%$ do sistema.

$\checkmark$ As instituições públicas cobrem o território nacional, apresentando um padrão mais disperso do que as privadas, que se concentram nas áreas metropolitanas de Lisboa e Porto e nas regiões com maior população.

$\checkmark$ A dimensão média das instituições públicas é de cerca de 6.800 alunos, enquanto no subsistema privado a dimensão média é de cerca de 920 alunos por instituição.

- As universidades públicas oferecem um total de 2.126 ciclos de estudos, com quase 70 mil vagas, e concentram, atualmente, cerca de 183 mil estudantes.

- Os institutos politécnicos públicos oferecem um total de 965 ciclos de estudos, com 35.512 vagas, e registam, atualmente, cerca de 109 mil estudantes inscritos.

- As universidades privadas oferecem 740 ciclos de estudos e 34.021 vagas, tendo, atualmente, cerca de 62 mil estudantes inscritos.

- Os institutos politécnicos privados oferecem 349 ciclos de estudos e têm, atualmente, cerca de 26 mil estudantes inscritos.

$\checkmark \quad$ Nos últimos três anos (2009 a 2011) as vagas disponíveis para ingresso no Ensino Superior público cresceram 3,9\%, o número de candidatos diminuiu $9,6 \%$ e os estudantes colocados representaram menos 6,8\% face a 2009. Em termos absolutos, na $1^{\mathrm{a}}$ fase do concurso de 2011 ficaram por ocupar 11248 vagas.

$\checkmark$ No mesmo período, as vagas disponíveis para ingresso no Ensino Superior privado diminuíram 10,5\% e os estudantes colocados representaram menos $4,1 \%$ em relação a 2009 . Em termos absolutos, na $1^{\mathrm{a}}$ fase do concurso de 2011 ficaram por ocupar 15.811 vagas. 


\section{Ameaças e oportunidades identificadas}

\begin{tabular}{|c|c|c|c|}
\hline \multicolumn{4}{|c|}{ AMBIENTE EXTERNO } \\
\hline \multicolumn{2}{|r|}{ OPORTUNIDADES } & \multicolumn{2}{|r|}{ AMEAÇAS } \\
\hline 1 & Internacionalização & 1 & Tendência demográfica \\
\hline 2 & Aprendizagem ao longo da vida & 2 & $\begin{array}{l}\text { Incerteza dos perfis de competência } \\
\text { futuros }\end{array}$ \\
\hline 3 & Agenda 2020 & 3 & $\begin{array}{l}\text { Indefinição do papel do Ensino Público } \\
\text { e do Ensino Privado }\end{array}$ \\
\hline 4 & Políticas de aumento da qualificação & 4 & $\begin{array}{l}\text { Desvalorização atribuída ao diploma do } \\
\text { Ensino Superior }\end{array}$ \\
\hline 5 & Mercado dos PALOP & 5 & $\begin{array}{l}\text { Ausência de políticas de gestão dos } \\
\text { Recursos Humanos }\end{array}$ \\
\hline 6 & Globalização e multiculturalismo & 6 & $\begin{array}{l}\text { Aumento da concorrência entre IES sem } \\
\text { regulamentação }\end{array}$ \\
\hline 7 & $\begin{array}{l}\text { Valorização pela sociedade das } \\
\text { competências desenvolvidas - } \\
\text { atitudes, comportamentos e valores }\end{array}$ & 7 & $\begin{array}{l}\text { Importância dada aos rankings } \\
\text { internacionais }\end{array}$ \\
\hline 8 & $\begin{array}{l}\text { Crescente papel dos movimentos de } \\
\text { cidadania }\end{array}$ & 8 & $\begin{array}{l}\text { Ausência de integração entre os ciclos } \\
\text { de Ensino (Básico, Secundário, Superior) }\end{array}$ \\
\hline 9 & $\begin{array}{l}\text { Novas áreas científicas e } \\
\text { interdisciplinaridade de saberes }\end{array}$ & 9 & $\begin{array}{l}\text { Ausência de estratégia política para o } \\
\text { Ensino Superior no país }\end{array}$ \\
\hline 10 & $\begin{array}{l}\text { Rede / Oferta do Ensino Superior em } \\
\text { Portugal }\end{array}$ & 10 & Crise financeira generalizada \\
\hline 11 & $\begin{array}{l}\text { Aumento de competitividade entre } \\
\text { IES }\end{array}$ & 11 & Modelo de Financiamento Público \\
\hline 12 & $\begin{array}{l}\text { Ensino Superior como motor de } \\
\text { desenvolvimento }\end{array}$ & 12 & $\begin{array}{l}\text { Incerteza na definição de critérios das } \\
\text { entidades reguladoras }\end{array}$ \\
\hline 13 & Desenvolvimento tecnológico & 13 & Divergência ensino/mercado \\
\hline 14 & Novas formas de aprendizagem & 14 & $\begin{array}{l}\text { Tendência de redução do financiamento } \\
\text { público }\end{array}$ \\
\hline 15 & $\begin{array}{l}\text { Existência de uma entidade } \\
\text { independente reguladora do Ensino } \\
\text { Superior (seguindo os padrões } \\
\text { internacionais em vigor) }\end{array}$ & 15 & Falta de cooperação entre as IES \\
\hline 16 & Rede alumni & & nas no Contexto das IES Privadas \\
\hline 17 & $\begin{array}{l}\text { Transferência de saber das IES para } \\
\text { tecido empresarial }\end{array}$ & 16 & $\begin{array}{l}\text { Lobby muito forte das IES Públicas junto } \\
\text { do poder político e da Comunidade } \\
\text { Europeia }\end{array}$ \\
\hline
\end{tabular}




\section{Palavras-chave}

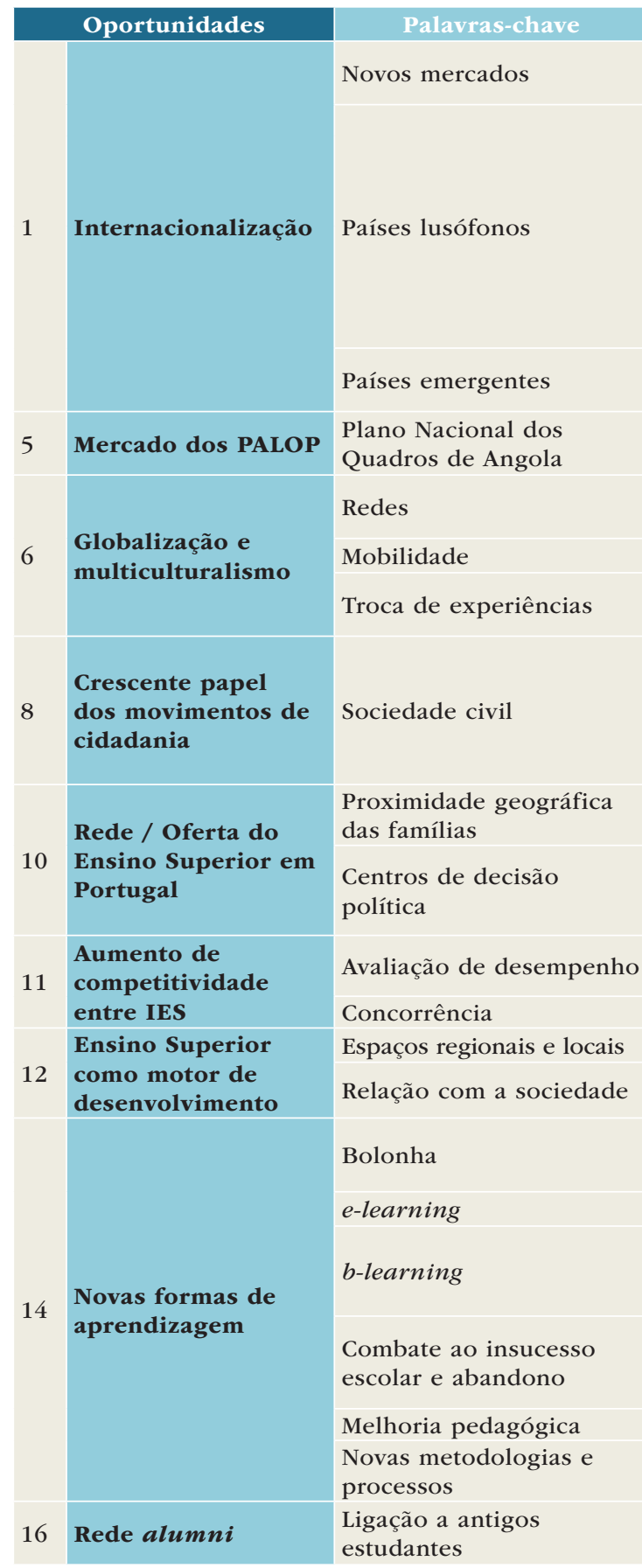

\begin{tabular}{|l|l|}
\hline \multicolumn{2}{|c|}{ Ameaças } \\
\hline 1 & $\begin{array}{l}\text { Tendência } \\
\text { demográfica }\end{array}$ \\
\hline
\end{tabular}

Indefinição do papel 3 do Ensino Público e do Ensino Privado

Desvalorização 4 atribuída ao diploma do Ensino Superior

Ausência de políticas 5 de gestão dos Recursos Humanos

Ausência de integração entre 8 os ciclos de Ensino (Básico, Secundário, Superior)

10

Crise financeira generalizada

Modelo de

11 financiamento público

15

Falta de cooperação entre IES

Incerteza dos perfis

12 de competência futuros
Palavras-chave

Envelhecimento

populacional

Assimetrias regionais

Países de leste - Ensino

Privado absorve excesso

do Ensino Público

Em alguns países

ocidentais o Ensino

Superior Privado é

dirigido a elites

Perceção negativa da sociedade

Empregabilidade dos diplomados

Congelamento das admissões e progressões Avaliação de desempenho Cortes de salários e aumento de impostos

Redução do número de estudantes que concluem o Ensino Secundário

Carência financeira das famílias

Dificuldades de financiamento dos estudantes

Espiral recessiva da economia

Lei dos compromissos

Restrições orçamentais

Investigação

Tendência de redução do financiamento público

Velocidade da mudança

Capacidade organizativa das IES na abordagem a novos mercados

Diplomacia académica Conselho Nacional de Ensino Superior (RJIES) 


\section{AM B I E NTE I N'TER NO}

\section{O que são pontos fortes e pontos fracos?}

Os pontos fortes correspondem a vantagens internas da organização relativamente às suas concorrentes. Os pontos fracos, por outro lado, dizem respeito a desvantagens internas da organização em relação às suas concorrentes.

Quer os pontos fortes, quer os pontos fracos, presume-se serem influenciáveis pela organização.

\section{Contributos iniciais}

\section{Reflexão individual dos membros do GT2}

Como base de discussão sobre o ambiente interno das IES, foi pedido aos membros do GT2 que dessem os seus contributos individuais acerca dos pontos fortes e pontos fracos das IES portuguesas. Estes contributos individuais serviram de base ao início da reflexão em grupo.

\section{Debate Interno - António Câmara}

Apresentação da sessão de reflexão Instituições do Ensino Superior enquanto organizações complexas: pontos fortes e pontos fracos. 


\section{Enquadramento: IES enquanto organizações complexas}

Esta fase do trabalho resultou de uma verdadeira "análise crítica coletiva”, em que cada participante trouxe à colação os pontos fortes e fracos pressentidos nas respetivas instituições, tendo em conta as cinco vertentes consideradas fundamentais para a elaboração desta fase da análise SWOT, a saber: tecnologia; pessoas; processos; estratégias; e meios (financeiros, humanos e materiais).

Os participantes foram divididos em dois grupos, optando-se por separar as IES públicas das privadas. Esta opção metodológica não resultou de qualquer entendimento, por parte do GT2, de que exista uma linha fraturante entre IES públicas e privadas face à essência das suas missões. No entanto, e para além de razões de ordem prática, considerou-se que seria mais produtivo que cada grupo pudesse debater de forma mais aprofundada as especificidades que a personalidade jurídica das suas instituições acarreta. Os resultados de cada reunião parcelar foram sendo discutidos e negociados em plenário, buscando-se consensos, eliminando-se redundâncias e afinando-se a formulação. Procurou-se, ainda, melhorar a leitura e articulação do quadro, ancorando cada um dos pontos identificados em palavras-chave que ajudam à sua qualificação e/ou identificam as grandes áreas de intervenção que lhes subjazem.

Pese embora a grande diversidade (geográfica, histórica, de dimensão, de subsistema) das IES envolvidas, o resultado final evidencia uma convergência de pontos fortes e fracos que parecem perpassar todo o sistema de Ensino Superior em Portugal, constatação que podemos classificar como talvez surpreendente, mas certamente animadora. Os benefícios desta análise interna dependerão, obviamente, da capacidade e vontade de cada uma das IES de a adaptar ao seu contexto específico; contudo, não será irrealista afirmar que também poderemos beneficiar de uma reflexão conjunta sobre a implementação e monitorização de estratégias de qualidade e melhoria contínua que esta análise SWOT pressupõe. 


\section{Pontos fortes e fracos identificados}

\section{AMBIENTE INTERNO}

PONTOS FORTES

Reconhecimento e reputação dos

1 diplomados portugueses (Massa crítica de talento de classe mundial)

2

Maturidade das instituições

3 Reforma de Bolonha consolidada

Qualidade reconhecida do Ensino

4 Superior a nível nacional e internacional

5 Prestígio da investigação

6 Diversidade de valências oferecidas

Participação crescente em redes

7 nacionais e internacionais de investigação

8 Serviços de apoio social

9 Diversidade de perfis de formação

10 Património tangível e intangível

11 Modelo de governação

12

Oferta formativa para a requalificação de ativos

13

Forte cooperação com o tecido empresarial e parceiros institucionais

14 Habilitação dos estudantes para o exercício de uma profissão

15 Qualidade do capital humano e tecnológico

16 Diversificação da produção científica

17 Prestação de serviços externos à comunidade

Credibilidade da gestão das IES portuguesas na prossecução da defesa do interesse público

19 IES consideradas força motriz para o desenvolvimento do país

Forte identificação dos estudantes com as instituições

\section{PONTOS FRACOS}

Escassez de mecanismos de remediação

1 das competências dos estudantes à entrada

Pouca mobilidade dos docentes e discentes entre instituições

Duplicação da oferta por um grande número de instituições

Escassez de oferta de unidades curriculares em língua estrangeira

5 Envelhecimento do corpo docente

6 Dependência de financiamento nacional não competitivo

Sistemas de informação insuficientes em áreas não tradicionais

8 Posição relativa nos rankings internacionais (na área da investigação)

9 Rigidez do corpo docente

10 Rigidez dos curricula

11 Qualidade da comunicação Isolamento de cada escola face às congéneres

Pouco investimento na ligação ao exterior

Número de investigadores a tempo integral insuficiente

15 Fraca investigação interdisciplinar

Insuficiente aposta ao nível do e-learning (referenciais de Qualidade) Ensino não fomenta criatividade e empreendedorismo

Ecossistema não compatível com os existentes nos principais centros mundiais (em termos de investigadores por exemplo) Fraca promoção do domínio da língua nativa

Sistema de "hard accountability"

20 (demasiado enfoque nos indicadores de performance) 
21

Forte orientação para a prestação do serviço ao estudante

22

Maior orientação prática dos cursos e adequação dos perfis ao mercado

Apenas no Contexto das IES Privadas

Cultura de proximidade das instituições

23 com os estudantes (relação professoraluno e outros)

24 Flexibilidade de gestão e potencial de eficiência organizativa
Apenas no Contexto das IES Privadas

21 Falta de cultura de investigação Transferências do saber (Existe

22 espaço para melhoria, por exemplo no aumento da investigação aplicada)

Desequilíbrio das áreas científicas da

23 oferta formativa ("mais cursos de papel e lápis")

24 Inexistência da carreira docente 


\section{Palavras-chave}

\begin{tabular}{|c|c|}
\hline & Pontos Fortes \\
\hline $\mathbf{1}$ & $\begin{array}{c}\text { Reconhecimento } \\
\text { e reputação } \\
\text { dos diplomados } \\
\text { portugueses }\end{array}$ \\
\hline $\mathbf{2}$ & $\begin{array}{c}\text { Maturidade das } \\
\text { instituições }\end{array}$ \\
\hline & reforma de Bolonha \\
\hline & consolidada \\
\hline & Rualidade reconhecida \\
\hline & $\begin{array}{c}\text { do Ensino Superior } \\
\text { a nível nacional e } \\
\text { internacional }\end{array}$ \\
\hline
\end{tabular}

6

Diversidade de valências oferecidas

10

Património tangível e intangível

Modelo de governação

12

Oferta formativa para a requalificação de ativos

IES consideradas

19 desenvolvimento do

país

Palavras-chave

qualidade

\section{reconhecimento}

resiliência e adaptabilidade

face à dinâmica

ciclos de estudo

adaptados a modelo

de Bolonha $(3+2)$ e

aprendizagem centrada no estudante

crescimento

consolidação da

Qualidade no século XXI

educação

cultura

caráter profissionalizante dos CE

oferta de estágios curriculares no $1 .^{\circ}$ ciclo

\section{bibliotecas}

apoio à comunidade

mais participado

princípios orientadores importantes

regime pós-laboral

ensino à distância

qualificação de mão de obra

inovação

Pontos Fracos

\section{Palavras-chave}

Escassez de mecanismos de remediação das competências dos estudantes à entrada

Duplicação da oferta por um grande número de instituições

\section{Escassez de oferta de} nidades curriculares em língua estrangeira

Rigidez do corpo docente

Rigidez nos curricula
11

\section{Qualidade da comunicação}

Isolamento de cada escola face às congéneres

Pouco investimento perfil socioeconómico dos estudantes

falta de colaboração interinstitucional

baixa mobilidade dentro do sistema

adaptação da oferta formativa à língua inglesa

qualificação insuficiente face aos novos requisitos de carreira [Politécnicos] carga letiva dos docentes problemas no alinhamento da formação dos docentes com áreas de lecionação problemas no alinhamento da formação das u.c. comunicação insuficiente entre áreas científicas

Ineficiências estruturais na utilização dos recursos comunicação interna comunicação externa pouca mobilidade dos docentes

falta de interação entre alunos, investigadores e pessoal não docente utilização do feedback dos empregadores e dos alumni ligação das empresas ao mercado de trabalho 
(Página deixada propositadamente em branco) 


\section{ENRIQUECIMENTO DA ANÁLISE SWOT}

Para além das sessões alargadas a toda a CS/11 para apresentação dos trabalhos e brainstorming, que ocorreram ao longo de 2013, constituíram ainda formas de enriquecimento da matriz SWOT as atividades referidas em seguida.

\section{Realização do inquérito aos estudantes}

Sendo o estudante o stakeholder central das IES, foi realizado um inquérito aos estudantes com assento nos órgãos de gestão das IES representadas no GT2.

O inquérito foi lançado a 2 de outubro de 2013 e contou com 95 respostas.

Neste inquérito, foi solicitado aos estudantes que atribuíssem prioridades aos resultados da análise SWOT quanto à sua importância (numa escala de 1 - nada importante a 5 - muito importante), bem como indicassem novos elementos que, no seu entender, devessem constar da matriz.

Da leitura das respostas aos inquéritos pode concluir-se que, em média, a priorização feita pelos estudantes apresentou resultados entre 3 e 4, de acordo com a escala de referência (1 a 5), em todas as entradas da matriz.

Depreende-se assim que, de uma forma geral, os estudantes concordaram com os elementos de ambientes interno e externo identificados pelo grupo.

\section{Encontro do GT2}

No Encontro do GT2 foram discutidas e recolhidas pelos participantes algumas sugestões que, após análise pelo grupo, foram incluídas neste trabalho. 


\section{Promotores}

Comissão Setorial para a Educação e Formação (CS/11)

Instituto Português da Qualidade (IPQ)

\section{Objetivos}

O Encontro teve como tema de fundo a análise SWOT do Sistema de Ensino Superior português, elaborada pelo GT2 durante o ano 2013 e teve como objetivos:

- partilhar os resultados desta análise com as comunidades académica, científica e técnica;

- promover o debate sobre as oportunidades, desafios e ações estratégicas inovadoras e de qualidade identificadas passíveis de implementar no Ensino Superior português.

\section{Destinatários}

Docentes do Ensino Superior; Dirigentes e Quadros Técnicos do Ensino Superior; Empregadores Nacionais, incluindo representantes das PME; Associações Profissionais; Associações Académicas; Representantes dos diversos setores da sociedade que interagem com o Ensino Superior português

Veja aqui o Programa do Encontro.

\section{Estrutura do Encontro}

Após uma introdução ao trabalho desenvolvido, com referência à metodologia e resultados da análise SWOT, o Encontro foi estruturado a 
partir de 3 estratégias de qualidade, correspondentes a 3 tópicos que o grupo considerou mais relevantes, e que originaram 3 painéis: Governança, Parcerias no Ensino Superior, e Redes e Cidadania.

A título de exemplo:

\section{PAINEL "GOVERNANÇA"}

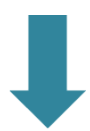

- Estabelecer critérios de atribuição de ECTS em atividades extracurriculares (ex: voluntariado)

- Criar modelos de referenciais de qualidade para o ensino a distância (A3ES)

- Marketing das IES portuguesas no mercado global - criar uma estratégia nacional

- Normalizar a afiliação da produção científica (ex: publicações) no sentido de valorizar a investigação no Ensino Superior

- Assegurar transparência, equidade e rigor nos critérios de financiamento público

PAINEL "PARCERIAS NO ENSINO SUPERIOR"

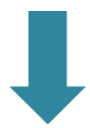

- Fortalecer oferta de Aprendizagem ao Longo da Vida, aproveitando parcerias através de pequenos módulos não conferentes de grau

- Criar programas de mobilidade internacional dos docentes, não docentes e discentes

- Criar plataforma de e-learning comum (partilha de tecnologia e capital humano)

- Criar um portfólio de serviços e oferta de formação direcionados para o meio empresarial 
- Criar Observatório do Cidadão em Rede para partilha e divulgação de boas práticas na área da Responsabilidade Social

- Criar programas atrativos de captação de mecenato (fundraising)

- Diversificar e aumentar os serviços prestados à comunidade

- Refletir/redefinir as interfaces das IES com a sociedade

\section{Comunicações dos oradores}

\section{ANÁLISE SWOT - GT2}

Professora Doutora Margarida Mano - Vice-Reitora da Universidade de Coimbra

\section{AMBIENTE EXTERNO - OPORTUNIDADES E AMEACAS}

Professor Especialista Henrique Pires - Diretor de Qualidade, Avaliação e Acreditação do IPAM

\section{AMBIENTE INTERNO - PONTOS FORTES E FRACOS}

Professora Doutora Cristina Pinto da Silva - Vice-Presidente do Instituto Politécnico do Porto

\section{GOVERNANÇ}

Professor Doutor Júlio Pedrosa

\section{PARCERIAS NO ENSINO SUPERIOR}

Professor Doutor Fernando Seabra Santos

\section{REDES E CIDADANIA}

Dra. Maria da Graça Gonçalves Neto

Dra. Helena Maria Areias 
Veja aqui a avaliação do Encontro pelos participantes.
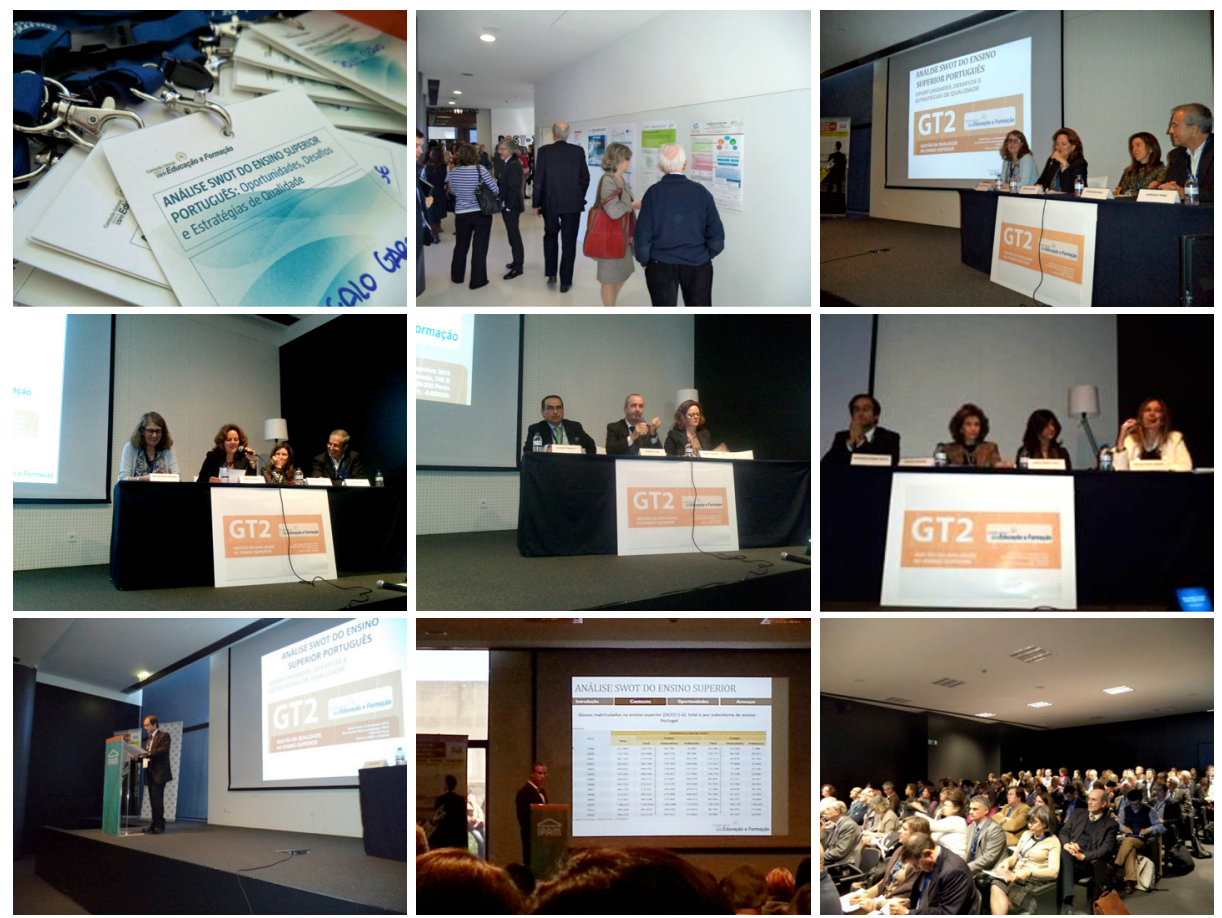

Notícias relacionadas com o evento

- Espaço Q

- Canal Superio

- Diário As Beiras

- Notícias ao minuto

- Notícias de Coimbra 


\section{ANÁLISE SWOT - RESULTADO FINAL}

\section{Ambiente interno externo}

\begin{tabular}{|c|c|c|c|}
\hline \multicolumn{4}{|c|}{ AMBIENTE EXTERNO } \\
\hline & OPORTUNIDADES & & AMEAÇAS \\
\hline I & Internacionalização & I & Tendência demográfica \\
\hline 2 & Aprendizagem ao longo da vida & 2 & Incerteza dos perfis de competência futuros \\
\hline 3 & Agenda 2020 & 3 & Indefinição do papel do Ensino Público e do Ensino Privado \\
\hline 4 & Políticas de aumento da qualificação & 4 & Desvalorização atribuída ao diploma do Ensino Superior \\
\hline 5 & Mercado dos PALOP & 5 & Ausência de políticas de gestão dos Recursos Humanos \\
\hline 6 & Globalização e multiculturalismo & 6 & Aumento da concorrência entre IES sem regulamentação \\
\hline 7 & $\begin{array}{c}\text { Valorização pela sociedade das competências desenvolvidas - } \\
\text { atitudes, comportamentos e valores }\end{array}$ & 7 & Importância dada aos rankings internacionais \\
\hline 8 & Crescente papel dos movimentos de cidadania & 8 & $\begin{array}{l}\text { Ausência de integração entre os ciclos de Ensino (Básico, } \\
\text { Secundário, Superior) }\end{array}$ \\
\hline 9 & Novas áreas científicas e interdisciplinaridade de saberes & 9 & Ausência de estratégia política para o Ensino Superior no país \\
\hline 10 & Rede / Oferta do Ensino Superior em Portugal & 10 & Crise financeira generalizada \\
\hline II & Aumento de competitividade entre IES & II & Modelo de Financiamento Público \\
\hline 12 & Ensino Superior como motor de desenvolvimento & 12 & Incerteza na definição de critérios das entidades reguladoras \\
\hline 13 & Desenvolvimento tecnológico & 13 & Divergência ensino/mercado \\
\hline 14 & Novas formas de aprendizagem & 14 & Tendência de redução do financiamento público \\
\hline 15 & $\begin{array}{l}\text { Existência de uma entidade independente reguladora do Ensino } \\
\text { Superior (seguindo os padrōes internacionais em vigor) }\end{array}$ & 15 & Falta de cooperação entre as IES \\
\hline 16 & Rede alumni & & Apenas no Contexto das IES Privadas \\
\hline 17 & Transferência de saber das IES para tecido empresarial & 16 & $\begin{array}{l}\text { Lobby muito forte das IES Públicas junto do poder político e da } \\
\text { Comunidade Europeia }\end{array}$ \\
\hline
\end{tabular}

AMBIENTE INTERNO

\section{PONTOS FORTES}

Reconhecimento e reputação dos diplomados portugueses (Massa crítica de tálento de classe mundial)

Maturidade das instituições

Reforma de Bolonha consolidada

Qualidade reconhecida do Ensino Superior a nível nacional e internaciona

Prestígio da investigação

Diversidade de valências oferecidas

Participação crescente em redes nacionais e internacionais de investigação

Serviços de apoio social

Diversidade de perfis de formação

Património tangível e intangível

Modelo de governação

Oferta formativa para a requalificação de ativos

Forte cooperação com o tecido empresarial e parceiros institucionais

4 Habilitação dos estudantes para o exercício de uma profissão

Qualidade do capital humano e tecnológico

Diversificação da produção científica

Prestação de serviços externos à comunidade

Credibilidade da gestão das IES portuguesas na prossecução

IES consideradas força motriz para o desenvolvimento do país

Forte identificação dos estudantes com as instituições

Forte orientação para a prestação do serviço ao estudante

Maior orientação prática dos cursos e adequação dos perfis ao mercado

\section{Apenas no Contexto das IES Privadas}

Cultura de proximidade das instituições com os estudantes (relação professor-aluno e outros)

\section{PONTOS FRACOS}

Escassez de mecanismos de remediação das competências dos Pouca mobilidade dos docentes e discentes entre instituições Duplicação da oferta por um grande número de instituições

Escassez de oferta de unidades curriculares em língua estrangeira

Envelhecimento do corpo docente

Dependência de financiamento nacional não competitivo

Sistemas de informação insuficientes em áreas não tracidionais

Posição relativa nos rankings internacionais (na área da investigação)

Rigidez do corpo docente

Rigidez dos curricula

Qualidade da comunicação

Isolamento de cada escola face às congéneres

Pouco investimento na ligação ao exterior

Número de investigadores a tempo integral insuficiente

Fraca investigação interdisciplinar Insuficiente aposta ao nível do e-learning (referenciais de
Qualidade)

Ensino não fomenta criatividade e empreendedorismo

Ecossistema não compatível com os existentes nos principais centros mundiais (em termos de investigadores por exemplo)

Fraca promoção do domínio da língua nativa

Sistema de "hard accountability" (demasiado enfoque nos indicadores de performance)

\section{Apenas no Contexto das IES Privadas}

Falta de cultura de investigação

Transferências do saber (Existe espaço para melhoria, por exemplo no aumento da investigação aplicada) Desequilibrio das áreas cientificas da ofertta formativa ("mais
cursos de papel e lápis")

Inexistência da carreira docente 


\section{Matriz SWOT - Sugestões de ação}

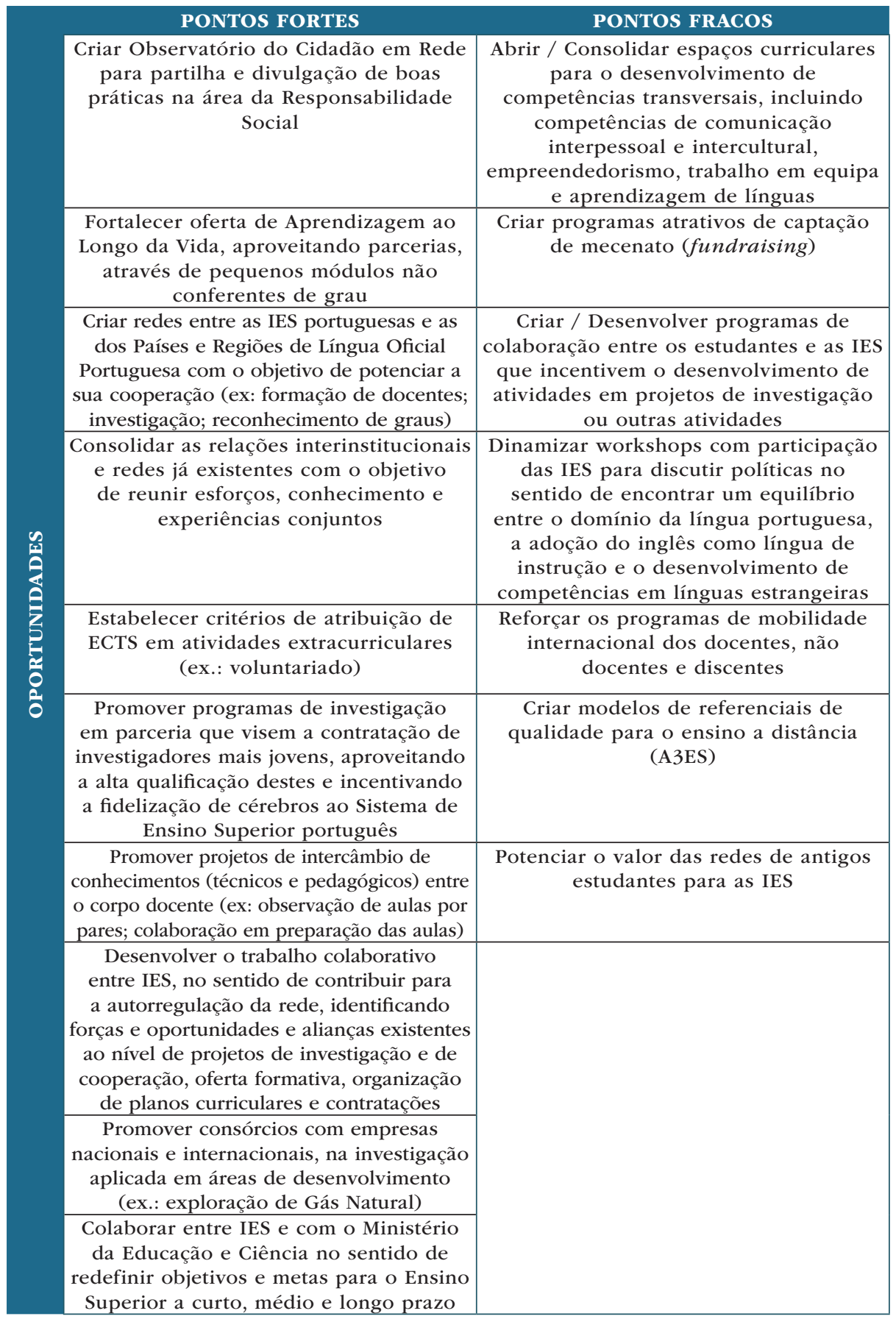




\begin{tabular}{|c|c|}
\hline Criar e desenvolver incubadoras & $\begin{array}{c}\text { Promover encontros / workshops entre } \\
\text { as várias IES para partilha de boas } \\
\text { práticas (CS/11 - GT2, A3ES, CRUP, } \\
\text { CCISP, APESP) }\end{array}$ \\
\hline $\begin{array}{l}\text { Criar um portfólio de serviços e oferta } \\
\text { de formação direcionados para o meio } \\
\text { empresarial }\end{array}$ & $\begin{array}{c}\text { Criar plataforma de e-learning comum } \\
\text { (partilha de tecnologia e capital } \\
\text { humano) }\end{array}$ \\
\hline $\begin{array}{c}\text { Desenvolver estudos e envolver } \\
\text { parceiros na construção dos curricula } \\
\text { sobre as necessidades de mercado } \\
\text { (empregabilidade) e apoiar a } \\
\text { constituição dos curricula de alguns } \\
\text { ciclos de estudos às mesmas }\end{array}$ & $\begin{array}{l}\text { Reforçar o número de unidades } \\
\text { curriculares lecionadas em inglês }\end{array}$ \\
\hline $\begin{array}{l}\text { Apostar na formação pós-graduada } \\
\text { como forma de requalificar profissionais } \\
\text { e desenvolver competências }\end{array}$ & $\begin{array}{l}\text { Normalizar a afiliação da produção } \\
\text { científica (ex.: publicações) no sentido } \\
\text { de valorizar a investigação no Ensino } \\
\text { Superior }\end{array}$ \\
\hline $\begin{array}{l}\text { Diversificar e aumentar os serviços } \\
\text { prestados à comunidade }\end{array}$ & $\begin{array}{c}\text { Promover a aquisição de competências } \\
\text { / atualização de necessidades } \\
\text { específicas à entrada (ex: avaliação de } \\
\text { competências específicas de cada curso } \\
\text { à entrada no ES, cursos de verão, ano } \\
\text { zero, criação de grupos de trabalho } \\
\text { entre instituições de ligação à IES e } \\
\text { escolas secundárias para promoção de } \\
\text { iniciativas) } \\
\end{array}$ \\
\hline $\begin{array}{c}\text { Marketing das IES portuguesas no } \\
\text { mercado global - criar uma estratégia } \\
\text { nacional }\end{array}$ & $\begin{array}{c}\text { Assegurar transparência, equidade e } \\
\text { rigor nos critérios de financiamento } \\
\text { público }\end{array}$ \\
\hline $\begin{array}{c}\text { Aproveitar o potencial de mercados } \\
\text { emergentes através da investigação e da } \\
\text { língua portuguesa }\end{array}$ & $\begin{array}{l}\text { Fomentar a articulação institucional } \\
\text { entre a oferta de cursos por regiões (ex: } \\
\text { criação de fóruns regionais de discussão } \\
\text { da gestão de topo das IES) tendo em } \\
\text { vista a criação de estratégias integradas }\end{array}$ \\
\hline & $\begin{array}{l}\text { Conjugar estratégias de recursos } \\
\text { humanos com uma cultura de } \\
\text { investigação de excelência }\end{array}$ \\
\hline & $\begin{array}{l}\text { Refletir / Redefinir as interfaces das IES } \\
\text { com a sociedade }\end{array}$ \\
\hline & $\begin{array}{c}\text { Aumentar a participação dos } \\
\text { stakeholders na definição da oferta } \\
\text { formativa e em projetos de investigação } \\
\text { a desenvolver }\end{array}$ \\
\hline
\end{tabular}




\section{QUALI DA DE E OPORTUNIDADES NO ENSINO S U P E R I O R}

O empenho demonstrado na elaboração de um documento SWOT sobre o Ensino Superior revelou a urgência na enunciação e prossecução de medidas refletoras de princípios essenciais à implementação de sistemas de Garantia da Qualidade, suportadas em referenciais e indicadores precisos.

Partindo de contributos dados pela equipa envolvida na elaboração do documento final da análise SWOT, acrescida e enriquecida pelas sugestões dos participantes no fórum de discussão ("Análise SWOT do Ensino Superior Português: Oportunidades, Desafios e Estratégias de Qualidade”, Porto, 13 de novembro de 2013), foi construída uma grelha de sistematização que procura enquadrar esses contributos em grandes áreas-chave de referência. 


\begin{tabular}{|c|c|c|}
\hline $\begin{array}{l}\text { DOMÍNIOS DE } \\
\text { INTERVENCÃO }\end{array}$ & & REFERENCIAIS A CONSIDERAR \\
\hline $\begin{array}{l}\text { Politica de } \\
\text { Qualidade }\end{array}$ & $\checkmark$ & $\begin{array}{l}\text { Políticas de aumento de qualificação } \\
\text { Existência de uma entidade independente do ES (seguindo } \\
\text { padrões internacionais em vigor) } \\
\text { Modelos de governança (flexibilidade de gestão e potencial } \\
\text { de eficiência organizativa) } \\
\text { Criação de Observatório do cidadão em rede para partilha de } \\
\text { boas práticas } \\
\text { Estudos para desenvolver curricula, articulados com as } \\
\text { necessidades do mercado } \\
\text { Estratégias de marketing das IES }\end{array}$ \\
\hline $\begin{array}{l}\text { Qualidade da } \\
\text { oferta formativa }\end{array}$ & $\begin{array}{l}\checkmark \\
\checkmark \\
\checkmark \\
\checkmark \\
\checkmark\end{array}$ & $\begin{array}{l}\text { Redes de oferta formativa } \\
\text { Diversidade das valências oferecidas } \\
\text { Diversidade de perfis de formação } \\
\text { Maior orientação prática dos cursos e adequação dos perfis } \\
\text { ao mercado (estágios e caráter profissionalizante dos cursos) } \\
\text { Novas áreas científicas e interdisciplinaridade } \\
\text { E-learning e b-learning } \\
\text { Articulação dos fatores proximidade } \\
\text { Avaliação do desempenho/ impacto da formação } \\
\text { Análise da concorrência }\end{array}$ \\
\hline $\begin{array}{l}\text { Política de } \\
\text { investigação }\end{array}$ & $\begin{array}{l}\checkmark \\
\checkmark \\
\checkmark\end{array}$ & $\begin{array}{l}\text { Prestígio da investigação } \\
\text { Diversificação da produção científica } \\
\text { Rede nacional e internacional do mérito científico dos } \\
\text { investigadores } \\
\text { Conhecer o potencial dos mercados emergentes } \\
\text { Promoção de programas de investigação com contratação } \\
\text { de jovens investigadores (incentivar a fidelização de cére- } \\
\text { bros) Promover o intercâmbio de conhecimentos entre o } \\
\text { corpo docente } \\
\text { Promover consórcios de investigação com empresas nacio- } \\
\text { nais e internacionais }\end{array}$ \\
\hline $\begin{array}{l}\text { Qualidade na } \\
\text { abordagem } \\
\text { pedagógica }\end{array}$ & $\begin{array}{l}\checkmark \\
\checkmark\end{array}$ & $\begin{array}{l}\text { Aposta em novos modelos de aprendizagem (b-learning, } \\
\text { e-learning, novas metodologias e processos pedagógicos } \\
\text { e andragógicos) } \\
\text { Combate ao abandono escolar } \\
\text { Aproveitamento de parcerias, através de pequenos módulos, } \\
\text { não conferentes de grau académico }\end{array}$ \\
\hline $\begin{array}{l}\text { Qualidade na } \\
\text { interação com a } \\
\text { envolvente externa }\end{array}$ & $\begin{array}{l}\checkmark \\
\checkmark \\
\checkmark\end{array}$ & $\begin{array}{l}\text { Aprendizagem ao longo da vida } \\
\text { Requalificação de ativos } \\
\text { Agenda } 2020\end{array}$ \\
\hline $\begin{array}{l}\text { Qualidade nos } \\
\text { serviços de apoio e } \\
\text { recurso }\end{array}$ & $\begin{array}{l}\checkmark \\
\checkmark \\
\checkmark\end{array}$ & $\begin{array}{l}\text { Bibliotecas } \\
\text { Apoio à comunidade estudantil } \\
\text { Serviços de ação social }\end{array}$ \\
\hline $\begin{array}{l}\text { Qualidade na } \\
\text { internacionalização } \\
\text { e multiculturalismo }\end{array}$ & $\begin{array}{l}\checkmark \\
\checkmark \\
\checkmark \\
\end{array}$ & $\begin{array}{l}\text { Abertura a novos mercados } \\
\text { Alargamento a novos países (lusófonos, PALOP e emergentes) } \\
\text { Criação de redes de oferta do ES (formação de docentes, } \\
\text { investigação, reconhecimento de graus) } \\
\text { Mobilidade } \\
\text { Intercâmbio de experiências } \\
\text { Interdisciplinaridade do saber }\end{array}$ \\
\hline $\begin{array}{l}\text { Qualidade na } \\
\text { informação e } \\
\text { projeção da imagem }\end{array}$ & $\begin{array}{l}\checkmark \\
\checkmark \\
\checkmark \\
\checkmark \\
\checkmark\end{array}$ & $\begin{array}{l}\text { Valorização de competências saídas da universidade } \\
\text { Reconhecimento e reputação dos diplomados } \\
\text { Qualidade reconhecida do ES a nível nacional e internacional } \\
\text { Forte identificação dos estudantes com as instituições ES } \\
\text { Marketing das IES no mercado global }\end{array}$ \\
\hline
\end{tabular}




\section{Para onde evoluir?}

Da análise SWOT resultou uma matriz de ações/sugestões, rica em iniciativas estratégicas, que pretendem reduzir o impacto das ameaças e pontos fracos e potenciar as vantagens das oportunidades e pontos fortes encontrados. Salienta-se nesta matriz uma grande ênfase na partilha de conhecimentos, na criação de parcerias e de redes de cooperação que permitam um maior aproveitamento dos recursos e o potenciar das sinergias.

Foram identificados 22 pontos fracos e 16 ameaças, destacando-se:

$\checkmark$ a fraca mobilidade entre instituições dos docentes e discentes;

$\checkmark$ a duplicação da oferta por um grande número de instituições;

$\checkmark \quad \mathrm{o}$ isolamento de cada escola face às congéneres;

$\checkmark$ e os problemas decorrentes da evolução demográfica e do contexto económico.

Na análise dos pontos fortes do Ensino Superior português, fica realçada:

$\checkmark$ a maturidade e qualidade reconhecida internacionalmente das IES Portuguesas;

$\checkmark \quad$ a qualidade dos seus recursos;

$\checkmark \quad$ o prestígio da investigação;

$\checkmark$ a qualidade dos diplomados;

$\checkmark$ e a participação crescente em redes e cooperação com o tecido empresarial.

$\mathrm{Na}$ análise do ambiente externo surgem como oportunidades:

\footnotetext{
$\checkmark$ a internacionalização;

$\checkmark \quad$ o próximo QREN (Portugal 2020);

$\checkmark$ a formação ao longo da vida;

$\checkmark$ novas formas de aprendizagem (como o e-learning);

$\checkmark \quad$ o desenvolvimento das redes alumni (antigos alunos);
} 
$\checkmark$ e a transferência de saber das universidades e politécnicos para o mercado de trabalho.

Ao confrontar as ameaças com as oportunidades para o Ensino Superior, surgiram como sugestões:

$\checkmark$ a colaboração e cooperação externa, não só em países de língua portuguesa mas também em países emergentes;

$\checkmark$ a colaboração interna/nacional entre IES;

$\checkmark$ e a promoção de ofertas formativas com entidades parceiras internacionais.

Neste sentido, a globalização e o multiculturalismo são vistos, em estreita relação com a internacionalização, como uma área de crescimento e desenvolvimento do Ensino Superior.

Fomentar a articulação institucional entre a oferta de cursos por regiões e redefinir os tipos de interfaces das IES com a sociedade; criar um observatório do cidadão em rede para partilha e divulgação de boas práticas no âmbito da responsabilidade social; dar maior visibilidade e mais valorização à investigação que se faz no Ensino Superior; assegurar a transparência, equidade e rigor na gestão do ensino público e privado; diversificar e aumentar os serviços prestados à comunidade; e capacitar os recursos humanos à necessária internacionalização, são outras das sugestões relevantes que surgem na sequência desta análise.

Em suma, este trabalho reforçou antes de mais os objetivos do GT2 com uma partilha aberta e informada entre as várias instituições do grupo, que será certamente muito útil nas suas reflexões estratégicas. A análise consensual e conjunta feita por todos os representantes, foi conseguida no final de um longo, intenso e rico debate, que contemplou as IES na sua complexidade e sonhos nas mais variadas vertentes, recaindo com especial incidência nas questões da internacionalização, da ligação à sociedade e da transferência de tecnologia.

Foram tidas em conta as movimentações internacionais, os problemas e desafios de hoje, tais como a demografia, o emprego, o papel do Estado, 
a transparência, a regulação e a garantia de qualidade, a governança da rede de Ensino Superior, as funções dos órgãos de gestão, entre outras. As sugestões de melhoria refletem as atuais tendências, que cada vez mais apontam para a colaboração entre IES, empresas, entidades nacionais e internacionais, públicas e privadas. É neste sentido que o GT2 vai adotar, como tema principal do trabalho a desenvolver ao longo do ano de 2014, a interface IES/Mercado de trabalho, com uma reflexão sobre as estratégias e instrumentos utilizados. O Grupo aproveita para explorar uma ou mais sugestões de melhoria propostas no âmbito da análise SWOT realizada, dando seguimento a uma das conclusões do evento de novembro, que propunha, precisamente, a consolidação e aproveitamento das relações interinstitucionais e redes já existentes com vista ao desenvolvimento de parcerias e projetos conjuntos. 
IMPRENSA DA UNIVERSIDADE DE COIMBRA COIMBRA UNIVERSITY PRESS

2014 